\title{
Management of Brain Metastases in Epidermal Growth Factor Receptor Mutant Non-Small-Cell Lung Cancer
}

\author{
William J. Kelly, Neil J. Shah and Deepa S. Subramaniam* \\ Division of Hematology-Oncology, Georgetown University, Washington, DC, United States
}

Lung cancer remains a leading cause of mortality with 1.69 million deaths worldwide. Activating mutations in epidermal growth factor receptor (EGFR), predominantly exon 19 deletions and exon 21 L858R mutations, are known oncogenic drivers identified in 20-40\% of non-small-cell lung cancers (NSCLC). $70 \%$ of EGFR-mutant NSCLC patients develop brain metastases (BM), compared to 38\% in EGFR wild-type patients. Firstgeneration tyrosine kinase inhibitors (TKIs), such as erlotinib and gefitinib have proven to be superior to chemotherapy in the front-line treatment of EGFR-mutant NSCLC, as has

OPEN ACCESS

Edited by:

Miguel Angel Villalona, Baptist Health South Florida,

United States

Reviewed by:

Joel W. Neal,

Stanford University, United States

Rabab Mohamed Gaafar,

Cairo University, Egypt

Gregory Alan Otterson,

The Ohio State University,

United States

*Correspondence:

Deepa S. Subramaniam

dss26@gunet.georgetown.edu

Specialty section:

This article was submitted to Thoracic Oncology,

a section of the journal

Frontiers in Oncology

Received: 01 February 2018

Accepted: 22 May 2018

Published: 03 July 2018

Citation:

Kelly WJ, Shah NJ and

Subramaniam DS (2018)

Management of Brain Metastases

in Epidermal Growth Factor

Receptor Mutant Non-

Small-Cell Lung Cancer.

Front. Oncol. 8:208.

doi: 10.3389/fonc.2018.00208 afatinib, a second-generation TKI. The most common acquired resistance mechanism is the development of a gatekeeper mutation in exon 20 T790M. Osimertinib has emerged as a third-generation EGFR TKI with proven activity in the front-line setting as well as in patients with a T790M acquired resistance mutation with remarkable CNS activity. As long-term survival outcomes in EGFR-mutant NSCLC continue to improve, the burden of BM becomes a greater challenge. Here, we review the literature related to the management of BM in EGFR-mutant NSCLC including the role of the three generations of EGFR TKIs, immunotherapy, and brain radiation.

\section{Keywords: epidermal growth factor receptor, non-small-cell lung cancer, brain metastases, targeted therapy, osimertinib \\ OVERVIEW OF BRAIN METASTASES IN EPIDERMAL GROWTH FACTOR RECEPTOR (EGFR) MUTANT NON-SMALL-CELL LUNG CANCER (NSCLC)}

\section{Epidemiology and Molecular Alterations in EGFR Mutant NSCLC}

Lung cancer remains a leading cause of mortality with 1.69 million deaths worldwide (1). An estimated 234,030 new cases will occur in the United States in 2018 with a median age at diagnosis of 70 and $64 \%$ predominance for males (2). Approximately $84 \%$ of these lung cancers are non-small cell lung cancers (NSCLC) (3). NSCLC has traditionally been classified by histology (adenocarcinoma, squamous, and large cell) but the classification paradigm has evolved to incorporate molecular subtypes that guide treatment decision making.

Epidermal growth factor receptor (EGFR) is a transmembrane tyrosine kinase receptor which activates Jak, PI3K, ROS, and RAS pathways leading to cell survival $(4,5)$. The most common activating mutations are exon 19 deletions or point mutations in exon 21 via Leu858Arg (L858R) $(6,7)$. Reports of the prevalence of EGFR mutations in NSCLC ranges from $46.7 \%$ in the East Asian population as reported by Liu et al. (8) to 38.4\% (range 36.5-40.3\%) in China and $14.1 \%$ (range 12.7-15.5\%) in Europe seen in Zhang et al. (9) and 22\% in African Americans enrolled in the Lung Cancer Mutation Consortium (10). The landmark BR21 trial demonstrated the survival advantage in chemo-refractory NSCLC with the use erlotinib, a first-generation EGFR inhibitor (11). 
Subsequently, three additional drugs (gefitinib, afatinib, and osimertinib) have now been approved to treat newly diagnosed EGFR-mutated advanced NSCLC. Among NSCLC patients who progress on first- or second-generation EGFR TKI therapy, most do so through a unique gatekeeper mutation, viz. the exon 20 point mutation Thr790Met (T790M) in the ATP-binding site of EGFR (12). Incidence of the T790 gatekeeper mutation has been reported to be between 49 and $63 \%(13,14)$. The methionine side chain acts as a "gatekeeper" residue causing steric hindrance thus decreasing hydrophilicity and preventing tyrosine kinase binding (15). The T790M mutation also increases ATP affinity (16). Other rare mechanisms of TKI resistance include MET amplifications or mutations, HER2 amplifications, and rarely BRAF mutations (12). Additionally, transformation to small cell histology is another possible mechanism of EGFR TKI resistance (13).

\section{Prevalence of Brain Metastases (BM) in EGFR-Mutant NSCLC}

Among NSCLC patients, those with BM have an increased frequency of EGFR mutations than those without brain metastasis and conversely, among EGFR mutant NSCLC patients the incidence of $\mathrm{BM}(70 \%)$ greatly surpasses the incidence of $\mathrm{BM}$ in wild-type (wt) EGFR NSCLC patients (38\%) (17). Approximately, one-third of EGFR-mutant NSCLC patients develop central nervous system (CNS) progression during the course of their illness (18). Among Asian populations, the prevalence of EGFR mutations in NSCLC BM ranges from 39 to 63\% (19, 20). Among North American and European populations this ranges from 2 to $40 \%(21,22)$. At initial diagnosis, EGFR mutation discordance estimates between primary and BM range are minimal (23). Prevalence of T790M mutations in CNS lesions among EGFR mutant NSCLC patients with TKI failure is much lower than anticipated at around $17 \%(24)$. This may reflect a pharmacokinetic failure of the first-generation EGFR TKIs to penetrate the brain and thus induced acquire resistance via the gatekeeper T790M mutation. Case reports have detailed patients on gefitinib and erlotinib, first-generation TKIs with modest brain penetrance, who have developed T790M-mediated resistance at primary tumor locations but not in the brain metastasis $(25,26)$. CNS progression appears to be higher in those with L858R point mutations (18). Interestingly, a retrospective radiologic analysis of 57 NSCLC patients suggested that exon 19 deleted patients may have more of a miliary pattern of BM (27). Table 1 summarizes the prospective trials of three generations of EGFR tyrosine inhibitors in EGFR-mutant NSCLC with BM.

\section{FIRST-GENERATION TYROSINE KINASE INHIBITORS (TKIs)}

\section{Erlotinib}

Erlotinib is a first-generation (EGFR) tyrosine kinase inhibitor (TKI) (28). The drug reduces EGFR autophosphorylation in intact tumor cells at a median inhibitory concentration of $20 \mathrm{nM}$ although this ranges from $5(\mathrm{nM})$ and $6(\mathrm{nM})$ in exon 19 deletion and L858R cell models respectively to $>2,000$ (nM) in T790M models (29, 30). High-performance liquid chromatography studies have shown that erlotinib penetrates the cerebrospinal fluid (CSF) at a rate of between $2(67 \mathrm{nM})$ and $4 \%(31,32)$. Radiolabeled ${ }^{11} \mathrm{C}$-erlotinib injected to one NSCLC patient was shown to accumulate in brain metastasis (33). Additionally, the average concentrations of erlotinib in CSF appear to be higher in those with partial responses (PRs) $(35 \mathrm{ng} / \mathrm{ml})$ compared to those who have progressive disease (16 $\mathrm{ng} / \mathrm{ml})$ (32).

Several studies have evaluated the effect of erlotinib in NSCLC patients with BM. Deng et al. reported on six unselected NSCLC patients with BM treated with erlotinib and noted that four of the six harbored an EGFR mutation in the tumor; two PRs and two stable diseases (SD) were noted in EGFR mutant patients (32).

TABLE 1 | Prospective studies in epidermal growth factor receptor (EGFR) mutant non-small-cell lung cancers (NSCLC) patients with brain metastases (BM).

\begin{tabular}{|c|c|c|c|c|c|}
\hline Study & Phase & $\begin{array}{l}\text { Tyrosine kinase } \\
\text { inhibitors therapy }\end{array}$ & $\begin{array}{l}\text { EGFR mutant NSCLC patients } \\
\text { with BM (unless specified) }\end{array}$ & Response rate (\%) & Survival (months) \\
\hline Park 2012 & $\|$ & Erlotinib or gefitinib & 28 & $\begin{array}{l}\text { Partial Response (PR): } 83 \\
\text { Stable Disease (SD): } 11\end{array}$ & $\begin{array}{l}\text { Progression-free survival } \\
\text { (PFS): } 6.6 \\
\text { Overall Survival (OS): } 15.9\end{array}$ \\
\hline Yu 2017 & 1 & Pulsatile erlotinib & 34 (only 32\% had brain mets) & $\begin{array}{l}\text { Complete Response (CR): } 2 \\
\text { PR: } 70\end{array}$ & PFS: 9.9 \\
\hline luchi 2013 & $\|$ & Gefitinib & 41 & Objective response rate (ORR): 88 & $\begin{array}{l}\text { PFS: } 14.5 \\
\text { OS: } 21.9\end{array}$ \\
\hline Yang 2017 (BRAIN) & III & Icotinib & 85 & - & Intracranial PFS: 10.0 \\
\hline Schuler 2016 (LUX-Lung 3/6) & III & Afatinib & $25 / 46$ & - & PFS: $11.1 / 8.2$ \\
\hline Park 2016 (LUX-Lung 7) & $\|$ & Afatinib & 26 & - & 8.4 \\
\hline Mok 2017 (AURA 3) & II & Osimertinib & 144 (T790M mut) & - & PFS: 8.5 \\
\hline Goss 2017 (AURA/AURA2) & $\|$ & Osimertinib & 50 (T790M mut) & Central nervous system (CNS) ORR: 54 & - \\
\hline Yang 2017 (BLOOM) & 1 & Osimertinib & 32 (LM, 11 T790M mut) & ORR: 43 & - \\
\hline Soria 2017 (FLAURA) & III & Osimertinib & 53 & $\begin{array}{l}\text { ORR: } 75 \\
\text { CNS PD: } 6\end{array}$ & PFS: 15.2 \\
\hline
\end{tabular}


Porta et al. retrospectively reviewed 69 NSCLC with BM patients treated with erlotinib (34). 17 patients had EGFR mutations, $82 \%$ of whom had an objective response rate (ORR) to erlotinib including eight complete responses (CRs) as well as a median time to progression of 11.7 months compared to 5.8 in EGFR wt patients and an overall survival of 12.9 months versus 3.1, respectively (34). Moreover, no patients without EGFR mutations had an objective response (34). A phase II study prospectively evaluated EGFR mutant NSCLC patients treated with erlotinib or gefitinib and noted that $83 \%$ achieved a PR and $11 \%$ SD without a statistically significant difference in progression-free survival (PFS) (6.6 months) or overall survival (OS) (15.9) between the two TKIs (35).

Dose escalation has also been examined as a potential strategy to increase CNS permeability and overcome resistance. In a small but compelling retrospective case series of nine EGFR mutant lung cancer patients with brain or leptomeningeal metastases that occurred despite conventional dosing of an EGFR inhibitor, patients were treated with high dose "pulsatile" erlotinib (1,500 mg weekly) and a CNS partial response rate of $67 \%$ (6 of 9 patients) was noted; however, median time to CNS progression was only 2.7 months (36). Following this, a phase 1 study in 34 patients with EGFR mutant lung cancer treated with escalating pulse doses of erlotinib found the maximum tolerated dose to be $1,200 \mathrm{mg}$ given on days 1 and 2, with $50 \mathrm{mg}$ given on days 3-7 weekly and it should be noted that $32 \%$ of patients had BM at study entry and none of these patients had progression of an untreated CNS metastasis or new CNS lesions while on study (37).

The role of erlotinib in leptomeningeal disease has also been examined. A retrospective review of 25 NSCLC (9 with exon 21 EGFR mutation and 8 with exon 19 deletion) patients with leptomeningeal (LM) carcinomatosis treated with either erlotinib or gefitinib demonstrated that those treated with erlotinib had a cytologic conversion rate of $64.3 \%$ compared to $9.1 \%$ with gefitinib (38), suggesting greater activity of erlotinib over gefitnib in the setting of LM disease. In another series of NSCLC patients with leptomeningeal metastasis who had failed gefitinib treatment, all 6 patients with an EGFR mutation-derived clinical benefit with 3 PRs and 3 with SD (39). 1 patient whose tumor did not harbor an EGFR mutation developed progressive disease as the best response.

\section{Gefitinib}

Gefitinib, another first-generation EGFR TKI, is a substrate for the $P$-glycoprotein efflux pumps and the drug has a brain penetration rate of only $1 \%(40,41)$. There have been many retrospective reviews of NSCLC patients with BM treated with gefitinib. An old retrospective study of 14 NSCLC patients with BM observed $1 \mathrm{CR}(6 \%)$ and 5 PRs (33\%); this was done prior to the understanding of the role of EGFR mutation status on response to targeted therapies (42). Another report on 15 patients found an ORR of $60 \%$ (43). In 2009, a retrospective study of 23 Korean never-smoker patients with lung adenocarcinoma and brain metastasis without prior whole brain radiotherapy (WBRT) found that gefitinib or erlotinib without WBRT resulted in an intracranial response rate of $73.9 \%$, noting that the prevalence of EGFR mutations in Korean non-smoker NSCLC population is high (44). Following this, Zhang et al. retrospectively reviewed 43 Chinese EGFR mutant NSCLC patients with BM treated with gefitinib or erlotinib until extracranial lesion progression; an intracranial lesion ORR of $57 \%$ and PFS of 9.3 months was observed, with no statistically significant difference in OS between gefitinib versus erlotinib (45).

Multiple prospective studies have also shown efficacy of gefitinib in NSCLC patients with BM. In 2004, Ceresoli reported on 41 NSCLC patients with BM treated with gefitinib including 18 patients with prior WBRT and observed a partial response rate of only $10 \%$ (46). Chiu et al. conducted a prospective study in 57 unselected NSCLC with BM patients observing an ORR of $33 \%$ and PFS of 5 months (47). Similarly, a 2007 study by Wu et al. examined 40 unselected NSCLC with BM patients (23 with prior WBRT) and found a $32 \%$ ORR and PFS of 9 months (48). However, a phase II study in 21 Chinese NSCLC patients with BM treated with prior WBRT reported a much higher $81 \%$ ORR and a PFS of 10 months (49).

Subsequent studies focused on gefitinib's efficacy in NSCLC with $\mathrm{BM}$ patients who harbored EGFR-activating mutations. Iuchi reported in 2013 on a phase II trial of 41 Japanese lung adenocarcinoma patients with BM showing a brain metastasis ORR of $87.8 \%$ with 13 CRs (50). Stereotactic radiation and WBRT were required in 20 patients (50). Patients with exon 19 deletions had a statistically significant PFS and OS advantage compared to L858R mutations (50). While the results of many of these studies appeared to be promising, the results and thus, the potential efficacy of first-generation EGFR TKIs in patient with BM, need to be interpreted with caution given the small numbers of patients in these predominantly retrospective reports.

\section{Icotinib}

Icotinib, a first-generation TKI approved in China, has a median CSF penetration rate of $6.1 \%$ (51). The BRAIN study was a multicenter, open-label, parallel randomized controlled trial of 176 Asian EGFR mutant NSCLC patients with at least three brain lesions; patients treated with icotinib had a median intracranial PFS of 10.0 months compared to 4.8 months in those treated with whole brain irradiation plus concurrent or sequential chemotherapy, translating to a $44 \%$ risk reduction from intracranial progression or death, and making this a potentially promising option (52).

\section{SECOND-GENERATION TKIS}

\section{Afatinib}

Afatinib is an oral second-generation TKI which selectively and irreversibly blocks EGFR, HER2, and HER4 kinase activity (53-55). The LUX-Lung 3 was a phase III trial of front-line afatinib in EGFR mutant advanced or metastatic NSCLC (56). Subgroup analysis of 35 patients with asymptomatic BM showed a PFS of 11.1 months versus 5.4 months with cisplatin and pemetrexed (57). The LUX-Lung 6 study was an open label randomized, multicenter phase III trial of Asian patients with EGFR mutant advanced or metastatic lung cancer (58). Prespecified subgroup analysis of 46 asymptomatic BM patients revealed that 
PFS was improved from 8.2 to 4.7 months in those treated with gemcitabine and cisplatin (58). Those who received whole brain radiation therapy appeared to have better PFS benefit than those who did not receive radiation; however, among BM patients, rates of CNS progression were similar to chemotherapy in both the LUX-Lung 3 (45 vs 33\% chemotherapy) and LUX-Lung 6 (21.4 vs $27.8 \%$ ) (58).

Another study through the afatinib compassionate use program examined 100 NSCLC patients with BM and/or leptomeningeal disease who had progressed on platinum chemotherapy and a first-generation EGFR TKI, 74\% of whom had a documented EGFR mutation (59). Median time to treatment failure was 3.6 months and was similar to a matched group of 100 patients without CNS metastasis; $35 \%$ had cerebral response and one heavily pretreated patient with impressive leptomeningeal response and neurological recovery had a CSF concentration of nearly $1 \mathrm{nM}(59)$.

The LUX-Lung 7 study, which was an international, open label, randomized phase II trial comparing afatinib to gefitinib in EGFR mutant advanced or metastatic NSCLC patients, noted that PFS was longer with afatinib (11 months) than gefitinib (10.9 months) but not statistically significant among the subgroup of 26 patients (16\%) with asymptomatic brain metastasis (60). Thus, despite its promise as a second-generation irreversible EGFR targeted agent, afatinib did not pan out to be significantly superior to the first-generation agents in systemic disease (or CNS disease) and its use is limited by its greater toxicity profile, except in some of the less common EGFR mutations where data suggest better efficacy.

\section{Dacomitinib}

Dacomitinib, another second-generation TKI with activity against EFGR, HER2, and HER4 was studied in two double blind, multicenter, randomized phase III trials: BR.26 and ARCHER 1009 (61, 62). In BR.26, dacomitinib did not improve OS in patients who had previously received gefitinib or erlotinib; routine brain imaging was not done in this study (61). Similarly, in Archer 1009, dacomitinib was not superior to erlotinib in advanced or metastatic NSCLC and only $2 \%$ of patients in this trial had brain metastasis at baseline (62).

\section{THIRD-GENERATION TKIs}

\section{Osimertinib}

Osimertinib is an oral, irreversible EGFR TKI that targets the classical activating mutations as well as the gatekeeper resistance mutation, i.e., T790M (63). Preclinical models showed that osimertinib had greater penetration of the murine blood-brain barrier (BBB) than gefitinib, rociletinib, or afatinib and increased exposure by labeled radiography in cynomolgus monkey brains (64).

AURA 3 was a randomized, international, open-label, phase II trial of T790M positive advanced NSCLC patients who had progressed on front-line EGFR TKI therapy (63). 144 patients had CNS metastases and those who received osimertinib had a longer median PFS (8.5 months) than platinum-pemetrexed chemotherapy (4.2 months) with a hazard ratio of 0.32 (63). A pooled analysis of AURA extension and AURA2 trials in 50 patients with asymptomatic BM found a CNS ORR of $54 \%$ to osimertinib treatment with $12 \%$ having complete CNS response, with benefit also noted in patients who had not received prior radiotherapy to the brain (65).

The BLOOM study was a phase I trial of patients with CSF cytology confirmed leptomeningeal disease (66). Preliminary results of 32 treated patients (23 evaluable) found 10 had radiographic improvement and 13 with SD; additionally 7 of 8 symptomatic patients improved and, the geometric mean decrease in CSF EGFRm DNA copy was 57\% (66).

The FLAURA study is a phase III study in 556 EGFR mutant (exon 19 del or L858R) advanced NSCLC patients which randomized patients 1:1 to a standard of care EGFR TKI (erlotinib or gefitinib) or osimertinib (67). Patients with neurologically stable CNS metastases were allowed on this study, accounting for $21 \%$ of patients on this study (67). Front-line treatment with osimertinib resulted in improved median PFS (18.9 months) compared to standard EGFR TKI therapy with erlotinib or gefitinib (10.2 months); median OS data were not mature at the time of the PFS analysis (67). It should be noted that ORR of known/treated CNS metastasis at trial entry was $77 \%$ in the osimertinib-treated patients compared to $63 \%$ in the standard EGFR TKI patients (68). Response duration lasting $>$ or $=6$ months was noted in $88 \%$ of patients on the osimertinib arm, with a CR rate of $18 \%$, while no CRs were observed in the arm with standard EGFR TKI. This has led to the FDA approval of osimertinib in the United States as an option for the front-line treatment of EGFR-mutated NSCLC harboring exon 19 deletions or exon 21 L858R mutations.

\section{Rociletinib}

Rociletinib (CO1686) was a unique, oral, irreversible TKI designed for NSCLC patients with activity against activating EGFR mutations (L858R and Del 19) and the gatekeeper resistance mutation T790M. The CNS activity of rociletinib was poor compared to systemic disease $(69,70)$. Camidge et al. reported that 22 of 42 patients continued rociletinib for an average of 120 days after CNS disease progression, treated with brain radiation (70). The development of this drug has since been halted given the high risk-to-benefit ratio related to the hyperglycemia resulting from blockade of the insulin growth factor receptor. Importantly, rociletinib appears to have poor brain penetration with most patients on rociletinib coming off the drug for CNS progression. In a study of the clinical activity of osimertinib in 45 EGFR-mutant NSCLC patients previously treated with rociletinib, subsequent treatment with osimertinib still achieved a brain disease control rate (response $+\mathrm{SD}$ ) of $88 \%(71)$.

\section{MISCELLANEOUS TKIs}

\section{AZD3759}

AZD3759 in an oral EGFR TKI designed for CNS penetration with a ratio of unbound brain to unbound plasma concentration of $0.65(72,73)$. AZD3759 caused tumor regression in leptomeningeal and brain metastasis mouse models (73). Preliminary results 
of the phase I BLOOM study of 38 EGFR-mutant NSCLC with $\mathrm{BM}$ or leptomeningeal metastasis (LM) treated with AZD3759 showed an intracranial ORR of $63 \%$ and extracranial ORR of $50 \%$ (74). Trough CSF concentrations were above the IC90 for pEGFR (74). Further development of this drug is on hold given the highly promising results with osimertinib in the FLAURA trial.

\section{Tesevatinib}

Tesevatinib (KD019) is a novel, oral, reversible TKI, which inhibits EGFR, HER2/neu, and Src family nonreceptor tyrosine kinases. Preclinical studies demonstrated good blood-brain penetration of tesevatinib with brain/blood radioactivity of 1 at 6-24 h and brain/plasma ratio of 2.3-4.4 from 1 to $24 \mathrm{~h}$ after a dose of tesevatinib (75). The studies also reported good antitumor activity with extended median survival time by $20 \%$ in preclinical mice models. Considering the preclinical results, Berz $\mathrm{D}$ et al. enrolled NSCLC pts with EGFR activating mutation and BM $(n=4)$ or leptomeningeal metastases (LM) $(n=3)$ which had progressed after prior EGFR TKI therapy (76). The authors used RECIST 1.1 for BM measurement and response evaluation. Symptomatic LM disease was diagnosed with CSF cytology or MRI finding and response was measured by improvement in symptoms, CSF cytology, and/or MRI findings. One patient with BM had 19\% reduction of target lesion on day 23, and another patient had $57 \%$ reduction of target BM with resolution of LM symptoms and MRI findings on day 41 . Grade $\geq 3$ AEs were QTc prolongation, hypokalemia, dehydration, UTI, and ALT elevation.

\section{COMBINATORIAL/ALTERNATIVE TREATMENT APPROACHES}

\section{Combination EGFR TKI and Radiotherapy}

Brain metastasis are resistant to systemic chemotherapy due to the $\mathrm{BBB}$ which restricts passage of small, non-polar molecules, or those with receptor-mediated transport (77). Thus research has investigated whether radiation can enhance TKI efficacy. In preclinical models, EGFR TKIs have been shown to increase radiation responses by promoting radiation-induced apoptosis as well as inhibiting cellular cycling, DNA damage repair, accelerated repopulation, and angiogenesis (78-80).

Concurrent use of EGFR TKIs during radiotherapy remains in question. A retrospective study of 44 EGFR-mutant NSCLC treated with concurrent radiotherapy evaluated adverse events (AEs) (81). The most common AEs were rash (50\%), anorexia (18\%), and diarrhea (15\%) with two patients having grade $\geq 3$ rash (81). Radiation-related AEs included hydrocephalus (2 patients), pneumonitis ( 3 patients, one grade $\geq 3$ ), myocarditis ( 1 patient), radiodermatitis (3 patients), laryngopharyngitis (2 patients), esophagitis (2 patients), and enteritis (1 patient) (81). A metaanalysis of 9 retrospective studies and 1 randomized controlled trial examining WBRT with EGFR TKI versus WBRT alone or EGFR TKI therapy alone included 1,041 unselected NSCLC patients with $\mathrm{BM}$ (82). In comparing combination therapy versus EGFR TKI alone the hazard ratios showed improved intracranial PFS with EGFR TKI alone (82). In comparing combination therapy versus WBRT alone the combination therapy had significantly improved OS (HR 0.52), intracranial PFS (HR 0.36), and extracranial PFS (HR0.52) (82). In addition, another metaanalysis of 15 studies including 3 phase II and 1 phase II trials in 1,552 unselected NSCLC patients with BM found that combination radiotherapy and EGFR TKI had improved response rate and disease control rate than radiotherapy alone or chemotherapy (83). Combination therapy significantly prolonged time to CNS progression (HR 0.56) and median OS (HR 0.58) but increased AE including rash (83).

A 2015 meta-analysis examined 12 observational studies that exclusively included EGFR-mutant NSCLC patients with brain metastasis (84). The analysis found that upfront cranial radiation improved intracranial PFS and 2-year OS but more neurological AEs were noted (84). One retrospective review by Gerber et al. examined 222 EGFR-mutant NSCLC BM patients treated with erlotinib, or WBRT or stereotactic radiation (SRS) (85). Patients treated with SRS had an OS of 64 months which was statistically significantly longer than the erlotinib group with median OS of 26 months (85). The results are likely biased due to the selection of patients with lower intracranial disease burden for the SRS approach. The median time to intracranial progression was understandably longer in the WBRT arm than the upfront erlotinib arm (24 vs 16 months; $p=0.04$ ) (85). Another multiinstitutional analysis of 351 EGFR-mutant NSCLC patients with BM compared treatment with SRS followed by EGFR TKI, WBRT followed by EGFR TKI, or EGFR TKI followed by radiotherapy (SRS or WBRT) at intracranial progression (86). Those receiving SRS upfront had improved OS (46 months) compared to those receiving upfront WBRT followed by TKI (30 months), or upfront EGFR TKI (25 months) (86).

\section{Immunotherapy}

PD-1 blockade has revolutionized the treatment of lung cancer and has been shown to have intracranial responses. However, many of the landmark immunotherapy studies have excluded EGFR-mutant NSCLC patients or patients with BM. Early analysis from a non-randomized, open-label, phase II trial showed $33 \%$ brain metastasis response rate among 18 NSCLC with BM (87). However, only one patient in this study had EGFR mutation (87). In vitro studies have shown that PD-L1 protein expression is higher in EGFR-mutant NSCLC cell lines than in EGFR wt and expression of mutated EGFR can induce PD-L1 expression $(88,89)$. In NSCLC, estimates of brain metastasis PDL1 positivity (PDL1 tumor cell expression exceeding 5\%) have ranged from 12 to $52 \%(90-92)$ but this has not been well characterized in the EGFR-mutant population.

Given the potential for intracranial activity the question may arise if checkpoint inhibition has a role in EGFR-mutant NSCLC with BM. While there is a paucity of data for checkpoint inhibitors in this population, some extrapolation from EGFRmutant NSCLC is possible. A meta-analysis of Checkmate 057 (nivolumab), Keynote 010 (pembrolizumab), and POPLAR (atezolizumab) showed that immune checkpoint inhibition prolonged OS over docetaxel in EGFR wt but not EGFR-mutant NSCLC (93). As checkpoint inhibition does not appear superior to chemotherapy EGFR-mutant NSCLC, immunotherapies use in 
the EGFR-mutant NSCLC with BM population is likely equally reserved. Nevertheless, one should consider immunotherapy in later lines of therapy.

\section{Combinational EGFR TKI and Anti- Angiogenic Therapy}

Several studies have looked at combining EGFR TKI with vascular endothelial growth factor directed monoclonal antibody therapy (94). The BELIEF trial was an international, multicenter, single-arm phase II trial of 109 treatment-naïve, advanced or metastatic, EGFR-mutant, lung adenocarcinoma patients treated with the combination erlotinib and bevacizumab (95). 37 patients (33\%) harbored T790M mutations and 21 (19\%) had brain metastasis; the median PFS was 13.2 months overall and 8.8 months for patients with brain metastasis (95). One of the greatest concerns with bevacizumab use among brain metastatic patients has been CNS hemorrhage. While CNS hemorrhage carries high morbidity and mortality, the incidence of CNS hemorrhage among bevacizumab-treated patients is less than $0.2 \%$ (96). Ongoing studies are investigating the combination of osimertinib and bevacizumab in EGFR-mutant NSCLC with BM (NCT02971501).

\section{CONCLUSION}

In conclusion, patients with EGFR-mutant NSCLC are continuing to live longer with median overall survival of 30.9 months and nearly $15 \%$ of patients are alive at 5 years (97). As patients live longer, most of these patients are likely to develop BM and we will need optimal therapies with low toxicity to manage the BM. Based on the summary of literature to date (Table 1), it is the expert opinion of the authors that a CNS-active TKI such as osimertinib is the EGFR TKI of choice in newly diagnosed

\section{REFERENCES}

1. World Health Organization. Cause-Specific Mortality, 2000-2016. Global Summary Statistics. Available from: http://www.who.int/healthinfo/global_ burden_disease/estimates/en/ (Accessed: June 19, 2018).

2. NCI Surveillance, Epidemiology, and End Results Program. Cancer Stat Facts: Lung and Bronchus Cancer. Available from: https://seer.cancer.gov/statfacts/ html/lungb.html (Accessed: June 19, 2018).

3. American Cancer Society. Cancer Facts \& Figures 2017. Atlanta, Ga: American Cancer Society (2017).

4. Zheng HC. The molecular mechanism of chemoresistance in cancers. Oncotarget (2017) 8(35):59950-64. doi:10.18632/oncotarget.19048

5. Sordella R, Bell DW, Haber DA, Settleman J. Gefitinib-sensitizing EGFR mutations in lung cancer activate anti-apoptotic pathways. Science (2004) 305(5687):1163-7. doi:10.1126/science.1101637

6. Paez JG, Janne PA, Lee JC, Tracy S, Greulich H, Gabriel S, et al. EGFR mutations in lung cancer: correlation with clinical response to gefitinib therapy. Science (2004) 304(5676):1497-1450. doi:10.1126/science.1099314

7. Lynch TJ, Bell DW, Sordella R, Gurubhagavatula S, Okimoto RA, Brannigan BW, et al. Activating mutations in epidermal growth factor receptor underlying responsiveness of non-small-cell lung cancer to gefitinib. N Engl J Med (2004) 350(21):2129-39. doi:10.1056/NEJMoa040938

8. Liu L, Liu J, Shao D, Deng Q, Tang H, Liu Z, et al. Comprehensive genomic profiling of lung cancer using a validated panel to explore therapeutic targets in East Asian patients. Cancer Sci (2017) 108(12):2487-94. doi:10.1111/cas. 13410 advanced NSLC harboring exon 19 deletions or exon 21 L858R mutations, given not only its CNS response rate but the durability of the CNS control, in addition to compelling data with tripling of the median PFS. It would be hard to argue against our opinion that osimertinib is the drug of choice in patients with and without BM. That said, the data regarding the use of upfront SRS followed by EGFR TKI needs to be taken into account in personalizing treatment options for patients with EGFR-mutant NSCLC and BM. The EGFR-mutant NSCLC patient who presents with a solitary brain metastasis should still be considered for surgical resection followed by CNS-active EGFR TKI therapy such as osimertinib. Selected patients with CNS oligometastatic disease with large volume BM that are symptomatic may benefit from the Magnuson approach of using upfront SRS while those with military or multiple, small, and especially asymptomatic BM may be able to delay the need for radiation with the use of upfront EGFR TKIs such as osimertinib. Whole brain radiation should be an option that is reserved for refractory BM that have progressed beyond SRS and systemic therapies, thus delaying the onset of neurocognitive decline that almost inevitably follows such an approach. Novel WBRT techniques such as hippocampal sparing (RTOG 0933) or use of drugs such as memantine (RTOG 0614) may further help to reduce the long-term neurotoxicity of WBRT in these patients (98).

\section{AUTHOR CONTRIBUTIONS}

WK drafted epidemiology, prevalence, TKI, radiotherapy, immunotherapy, and anti-angiogenic therapy sections. NS provided literature review and drafted TKI sections. DS provided concept, design for paper, scientific review, and interpretation of data. All authors contributed to manuscript revision, read, and approved the submitted version.

9. Zhang YL, Yuan JQ, Wang KF, Fu XH, Han XR, Threapleton D, et al. The prevalence of EGFR mutation in patients with non-small cell lung cancer: a systematic review and meta-analysis. Oncotarget (2016) 7(48):78985-93. doi:10.18632/oncotarget.12587

10. Steuer CE, Behera M, Berry L, Kim S, Rossi M, Sica G, et al. Role of race in oncogenic driver prevalence and outcomes in lung adenocarcinoma: results from the Lung Cancer Mutation Consortium. Cancer (2016) 122(5):766-72. doi:10.1002/cncr.29812

11. Shepherd FA, Rodrigues Pereira J, Ciuleanu T, Tan EH, Hirsh V, Thongprasert S, et al. Erlotinib in previously treated non-small-cell lung cancer. $N$ Engl J Med (2005) 353:123-32. doi:10.1056/NEJMoa050753

12. Yu HA, Arcila ME, Rekhtman N, Sima CS, Zakowski MF, Pao W, et al. Analysis of tumor specimens at the time of acquired resistance to EGFR TKI therapy in 155 patients with EGFR mutant lung cancers. Clin Cancer Res (2013) 19(8):2240-7. doi:10.1158/1078-0432.CCR-12-2246

13. Sequist LV, Waltman BA, Dias-Santagata D, Digumarthy S, Turke AB, Fidias P, et al. Genotypic and histological evolution of lung cancers acquiring resistance to EGFR inhibitors. Sci Transl Med (2011) 3(75):75ra26. doi:10.1126/ scitranslmed.3002003

14. Kuiper JL, Heideman DA, Thunnissen E, Paul MA, van Wijk AW, Postmus PE, et al. Incidence of T790M mutation in (sequential) rebiopsies in EGFRmutated NSCLC-patients. Lung Cancer (2014) 85(1):19-24. doi:10.1016/j. lungcan.2014.03.016

15. Kobayashi S, Boggon TJ, Dayaram T, Janne PA, Kocher O, Meyerson M, et al. EGFR mutation and resistance of non-small-cell lung cancer to gefitinib. $N$ Engl J Med (2005) 352(8):786-92. doi:10.1056/NEJMoa044238 
16. Yun CH, Mengwasser KE, Toms AV, Woo MS, Grulich H, Wong KK, et al. The T790M mutation in EGFR kinase causes drug resistance by increasing the affinity for ATP. Proc Natl Acad Sci U S A (2008) 105(6):2070-5. doi:10.1073/ pnas.0709662105

17. Ge M, Zhuang Y, Zhou X, Huang R, Lian X, Zhan Q. High probability and frequency of EGFR mutations in in non-small cell lung cancer with brain metastases. J Neuroncol (2017) 135(2):413-8. doi:10.1007/s11060-017-2590-x

18. Heon S, Yeap BY, Britt GJ, Costa DB, Rabin MS, Jackman DM, et al. Development of central nervous system metastases in patients with advanced non-small cell lung cancer and somatic EGFR mutations treated with gefitinib or erlotinib. Clin Cancer Res (2010) 16(23):5873-82. doi:10.1158/10780432.CCR-10-1588

19. Gow CH, Chang YL, Hsu YC, Tsai MF, Wu CT, Yu CJ, et al. Comparison of epidermal growth factor receptor mutations between primary and corresponding metastatic tumors in tyrosine kinase inhibitor-naïve non-small-cell lung cancer. Ann Oncol (2009) 20(4):696-702. doi:10.1093/annonc/mdn679

20. Matsumoto S, Takahashi K, Iwakawa R, Matsuno Y, Nakanishi Y, Kohno T, et al. Frequent EGFR mutations in brain metastases of lung adenocarcinoma. In J Cancer (2006) 119(6):1491-4. doi:10.1002/ijc.21940

21. Sun M, Behrens C, Feng L, Ozburn N, Tang X, Yin G, et al. HER family receptor abnormalities in lung cancer brain metastases and corresponding primary tumors. Clin Cancer Res (2009) 15(15):4829-37. doi:10.1158/10780432.CCR-08-2921

22. Daniele L, Cassoni P, Bacillo E, Cappia S, Righi L, Volante M, et al. Epidermal growth factor receptor gene in primary tumor and metastatic sites from non-small cell lung cancer. J Thorac Oncol (2009) 4(6):684-8. doi:10.1097/ JTO.0b013e3181a52359

23. Burel-Vandenbos F, Ambrosetti D, Coutts M, Pedeutour F. EGFR mutation status in brain metastases of non-small cell lung carcinoma. J Neurooncol (2013) 111(1):1-10. doi:10.1007/s11060-012-0990-5

24. Hata A, Katakami N, Yoshioka H, Takeshita J, Tanaka K, Nanjo S, et al. Rebiopsy of non-small cell lung cancer patients with acquired resistance to epidermal growth factor receptor-tyrosine kinase inhibitor: comparison between $\mathrm{T} 790 \mathrm{M}$ mutation-positive and mutation-negative populations. Cancer (2013) 119(24):4325-32. doi:10.1002/cncr.28364

25. Jackman DM, Holmes AJ, Lindeman N, Wen PY, Kesari S, Borras AM, et al. Response and resistance in a non-small-cell lung cancer patient with epidermal growth factor receptor mutation and leptomeningeal metastases treated with high-dose gefitinib. J Clin Oncol (2006) 24(27):4517-20. doi:10.1200/ JCO.2006.06.6126

26. Clarke JL, Pao W, Wu N, Miller VA, Lassman AB. High dose weekly erlotinib achieves therapeutic concentrations in CSF and is effective in leptomeningeal metastases from epidermal growth factor receptor mutant lung cancer. J Neurooncol (2010) 99(2):283-6. doi:10.1007/s11060-010-0128-6

27. Sekine A, Kato T, Haqiwara E, Shinohara T, Komagata T, Iwasawa T, et al. Metastatic brain tumors from non-small cell lung cancer with EGFR mutations: distinguishing influence of exon 19 deletion on radiographic features. Lung Cancer (2012) 77(1):64-9. doi:10.1016/j.lungcan.2011.12.017

28. Dempke WC, Edvardsen K, Lu S, Reinmuth N, Reck M, Inoue A. Brain metastases in NSCLC-are TKIs changing the treatment strategy? Anticancer Res (2015) 35(11):5797-806.

29. Moyer JD, Barbacci EG, Iwata KK, Arnold L, Boman B, Cunningham A, et al. Induction of apoptosis and cell cycle arrest by CP-358,774, an inhibitor of epidermal growth factor receptor tyrosine kinase. Cancer Res (1997) 57(21):4838-48.

30. Kancha RK, von Bubnoff N, Peschel C, Duyster J. Functional analysis of epidermal growth factor receptor (EGFR) mutations and potential implications for EGFR targeted therapy. Clin Cancer Res (2009) 15(2):460-7. doi:10.1158/1078-0432.CCR-08-1757

31. Toagashi Y, Masago K, Masuda S, Mizuno T, Fukudo M, Ikemi Y, et al. Cerebrospinal fluid concentration of gefitinib and erlotinib inpatients with non-small cell lung cancer. Cancer Chemother Pharmacol (2012) 70(3): 399-405. doi:10.1007/s00280-012-1929-4

32. Deng Y, Feng W, Wu J, Chen Z, Tang Y, Zhang H, et al. The concentration of erlotinib in the cerebrospinal fluid of patients with brain metastasis from non-small-cell lung cancer. Mol Clin Oncol (2014) 2(1):116-20. doi:10.3892/ mco.2013.190

33. Weber B, Winterdahl M, Memon A, Sorensen BS, Keiding S, Sorensen L, et al. Erlotinib accumulation in brain metastases from non-small cell lung cancer: visualization by positron emission tomography in a patient harboring a mutation in the epidermal growth factor receptor. J Thorac Oncol (2011) 6(7):1287-9. doi:10.1097/JTO.0b013e318219ab87

34. Porta R, Sanchez-Torres JM, Paz-Ares L, Massuti B, Requart N, Mayo C, et al. Brain metastases from lung cancer responding to erlotinib: the importance of EGFR mutation. Eur Respir J (2011) 37(3):624-31. doi:10.1183/ 09031936.00195609

35. Park SJ, Kim HT, Lee DH, Kim KP, Kim SW, Suh C, et al. Efficacy of epidermal growth factor receptor tyrosine kinase inhibitors for brain metastasis in nonsmall cell lung cancer patients harboring either exon 19 or 21 mutation. Lung Cancer (2012) 77(3):556-60. doi:10.1016/j.lungcan.2012.05.092

36. Grommes C, Oxnard GR, Kris MG, Miller VA, Pao W, Holodny AI, et al. "Pulsatile" high-dose weekly erlotinib for CNS metastases from EGFR mutant non-small cell lung cancer. Neuro Oncol (2011) 13(12):1364-9. doi:10.1093/ neuonc/nor 121

37. Yu HA, Sima C, Feldman D, Liu LL, Vaitheesvaran B, Cross J, et al. Phase 1 study of twice weekly pulse dose and daily low-dose erlotinib as initial treatment for patients with EGFR-mutant lung cancers. Ann Oncol (2017) 28(2):278-84. doi:10.1093/annonc/mdw556

38. Lee E, Keam B, Kim DW, Kim TM, Lee SH, Chung DH. Erlotinib versus gefitinib for control of leptomenigeal carcinomatosis in non-small-cell lung cancer. J Thorac Oncol (2013) 8(8):1069-74. doi:10.1097/JTO.0b013e318294c8e8

39. Katayama T, Shimizu J, Suda K, Onozato R, Fukui T, Ito S, et al. Efficacy of erlotinib for brain and leptomeningeal metastasis in patients with lung adenocarcinoma who showed initial good response to gefitinib. J Thorac Oncol (2009) 4(11):1415-9. doi:10.1097/JTO.0b013e3181b62572

40. McGranahan T, Nagpal SA. Neuro-oncologist's perspective on management of brain metastases in patients with EGFR mutant non-small cell lung cancer. Curr Treat Options Oncol (2017) 18(4):22. doi:10.1007/s11864-017-0466-0

41. Chen Y, Wang M, Zhong W, Zhao J. Pharmacokinetic and pharmacodynamics study of Gefitinib in a mouse model of non-small-cell lung carcinoma with brain metastasis. Lung Cancer (2013) 82(2):313-8. doi:10.1016/j.lungcan. 2013.08.013

42. Hotta K, Kiura K, Ueoka H, Tabata M, Fujiwara K, Kozuki T, et al. Effect of gefitinib ('Iressa', ZD1839) on brain metastases in patients with advanced non-small-cell lung cancer. Lung Cancer (2004) 46(2):255-61. doi:10.1016/j. lungcan.2004.04.036

43. Namba Y, Kijima T, Yokota S, Ninaka M, Kawamura S, Iwasaki T, et al. Gefitinib in patients with brain metastases from non-small-cell lung cancer:review of 15 clinical cases. Clin Lung Cancer (2004) 6(2):123-8. doi:10.3816/CLC. 2004.n.026

44. Kim JE, Lee DH, Choi Y, Yoon DH, Kim SW, Suh C, et al. Epidermal growth factor receptor tyrosine kinase inhibitors as a first-line therapy for never-smokers with adenocarcinoma of the lung having asymptomatic synchronous brain metastasis. Lung Cancer (2009) 65(3):351-4. doi:10.1016/j. lungcan.2008.12.011

45. Zhang Q, Zhang X, Yan H, Jiang B, Xu C, Yang J, et al. Effects of epidermal growth factor receptor-tyrosine kinase inhibitors alone on EGFR-mutant non-small cell lung cancer with brain metastasis. Thorac Cancer (2016) 7(6):648-54. doi:10.1111/1759-7714.12379

46. Ceresoli GL, Cappuzzo F, Gregorc V, Bartolini S, Crinò L, Villa E. Gefitinib in patients with brain metastases from non-small-cell lung cancer: a prospective trial. Ann Oncol (2004) 15(7):1042-7. doi:10.1093/annonc/mdh276

47. Chiu CH, Tsai CM, Chen YM, Chiang SC, Liou JL, Perng RP. Gefitinib is active in patients with brain metastases from non-small cell lung cancer and response is related to skin toxicity. Lung Cancer (2005) 47(1):129-38. doi:10.1016/j.lungcan.2004.05.014

48. Wu C, Li YL, Wang ZM, Li Z, Zhang TX, Wei Z. Gefitinib as palliative therapy for lung adenocarcinoma metastatic to the brain. Lung Cancer (2007) 57(3):359-64. doi:10.1016/j.lungcan.2007.03.011

49. Ma S, Xu Y, Deng Q, Yu X. Treatment of brain metastasis from non-small cell lung cancer with whole brain radiotherapy and Gefitinib in a Chinese population. Lung Cancer (2009) 65(2):198-203. doi:10.1016/j.lungcan.2008.10.028

50. Iuchi T, Shingyoi M, Sakaida T, Hatano K, Nagano O, Itakura M, et al. Phase II trial of gefitinib alone without radiation therapy for Japanese patients with brain metastases from EGFR-mutant lung adenocarcinoma. Lung Cancer (2013) 82(2):282-7. doi:10.1016/j.lungcan.2013.08.016

51. Zhou L, He J, Xiong W, Liu Y, Xiang J, Yu Q, et al. Impact of whole brain radiation therapy on CSF penetration ability of Icotinib in EGFR-mutated 
non-small cell lung cancer patients with brain metastases: results of phase I dose-escalation study. Lung Cancer (2016) 96:93-100. doi:10.1016/j.lungcan. 2016.04.003

52. Yang JJ, Zhou C, Huang Y, Feng J, Lu S, Song Y, et al. Icotinib versus wholebrain irradiation in patients with EGFR-mutant non-small-cell lung cancer and multiple brain metastases (BRAIN): a multicenter, phase 3, open-label, parallel, randomized controlled trial. Lancet Respir Med (2017) 5(9):707-16. doi:10.1016/S2213-2600(17)30262-X

53. Li D, Ambrogio L, Shimamura T, Kubo S, Takahashi M, Chirieac LR, et al. BIBW2992, an irreversible EGFR/HER2 inhibitor highly effective in preclinical lung cancer models. Oncogene (2008) 27(34):4702-11. doi:10.1038/ onc.2008.109

54. Solca F, Dahl G, Zoephel A, Bader G, Sanderson M, Klein C, et al. Target binding properties and cellular activity of afatinib (BIBW 2992), an irreversible ErbB family blocker. J Pharmacol Exp Ther (2012) 343(2):342-50. doi:10.1124/jpet.112.197756

55. Subramaniam DS, Hwang J. BIBW 2992 in non-small cell lung cancer. Expert Opin Investig Drugs (2011) 20(3):415-22. doi:10.1517/13543784.2011. 557063

56. Sequist LV, Yang JC, Yamamoto N, O’Byrne K, Hirsh V, Mok T, et al. Phase III study of afatinib or cisplatin plus pemetrexed in patients with metastatic lung adenocarcinoma with EGFR mutations. J Clin Oncol (2013) 31(27):3327-34. doi:10.1200/JCO.2012.44.2806

57. Schuler M, Wu YL, Hirsh V, O'Byrne K, Yamamoto N, Mok T, et al. First-line afatinib versus chemotherapy in patients with non-small cell lung cancer and common epidermal growth factor receptor gene mutations and brain metastases. J Thorac Oncol (2016) 11(3):380-90. doi:10.1016/j.jtho.2015. 11.014

58. Wu YL, Zhou C, Hu CP, Feng J, Lu S, Huang Y, et al. Afatinib versus cisplatin plus gemcitabine for first-line treatment of Asian patients with advanced non-small-cell lung cancer harbouring EGFR mutations (LUX-Lung6): an open-label, randomized phase 3 trial. Lancet Oncol (2014) 15(2):213-22. doi:10.1016/S1470-2045(13)70604-1

59. Hoffknecht P, Tufman A, Wehler T, Pelzer T, Wiewrodt R, Schutz M, et al. Efficacy of the irreversible ErbB family blocker afatinib in epidermal growth factor receptor (EGFR) tyrosine kinase inhibitor (TKI)-pretreated non-smallcell lung cancer patients with brain metastases or leptomeningeal disease. J Thorac Oncol (2015) 10(1):156-63. doi:10.1097/JTO.0000000000000380

60. Park K, Tan EH, O’Byrne K, Zhange L, Boyer M, Mok T, et al. Afatinib versus gefitinib as first-line treatment of patients with EGFR mutation-positive non-small-cell lung cancer (LUX-Lung 7): a phase 2B, open-label, randomized controlled trial. Lancet Oncol (2016) 17(5):577-89. doi:10.1016/ S1470-2045(16)30033-X

61. Ellis PM, Shepherd FA, Millward M, Perrone F, Seymour L, Liu G, et al. Dacomitinib compared with placebo in pretreated patients with advanced or metastatic non-small-cell lung cancer (NCIC CTG BR.26): a double-blind, randomized, phase 3 trial. Lancet Oncol (2014) 15(12):1379-88. doi:10.1016/ S1470-2045(14)70472-3

62. Ramalingam SS, Janne PA, Mok T, O’Byrne K, Boyer MJ, Von Pawel J, et al. Dacomitinib versus erlotinib in patients with advanced-stage, previously treated non-small-cell lung cancer (ARCHER 1009): a randomised double-blind, phase 3 trial. Lancet Oncol (2014) 15(12):1369-78. doi:10.1016/ S1470-2045(14)70452-8

63. Mok TS, Wu Y-L, Ahn M-J, Garassino MC, Kim HR, Ramalingam SS, et al. Osimertinib or platinum-pemetrexed in EGFR T790M-positive lung cancer. N Engl J Med (2017) 376(7):629-40. doi:10.1056/NEJMoal612674

64. Ballard P, Yates JW, Yang Z, Kim DW, Yang JCC, Cantarini M, et al. Preclinical comparison of osimertinib with other EGFR-TKIs in EGFR-mutant NSCLC brain metastases models, and early evidence of clinical brain metastases activity. Clin Cancer Res (2016) 22(20):5130-40. doi:10.1158/1078-0432. CCR-16-0399

65. Goss G, Tsai CM, Shepherd F, Ahn MJ, Bazhenova L, Crino L, et al. MA16.11 CNS response to osimertinib in patients with T790M-positive advanced NSCLC: pooled data from two phase II trials. J Thorac Oncol (2017) Volume 12(Issue 1):S440-1. doi:10.1016/j.jtho.2016.11.514

66. Yang JCH, Cho BC, Kim DW, Kim SW, Lee JS, Su WC. Osimertinib for patients (pts) with leptomeningeal metastases (LM) from EGFR-mutant non-small cell lung cancer (NSCLC): Updated results from the BLOOM study. J Clin Oncol (2017) 35(no.15_suppl):2020-2020. doi:10.1200/JCO.2017.35.15_suppl.2020
67. Soria JC, Ohe Y, Vansteenkiste J, Reungwetwattana T, Chewaskulyong B, Lee KH, et al. Osimertinib in untreated EGFR-mutated advanced non-small-cell lung cancer. N Engl J Med (2018) 378(2):113-25. doi:10.1056/NEJMoa1713137

68. Osimertinib Prescribing Information. AstraZeneca Pharmaceuticals LP. Wilminton, DE. Available from: https://www.azpicentral.com/tagrisso/tagrisso. pdf\#page=1 (Accessed: June 8, 2018).

69. Sequist LV, Soria J-C, Goldman JW, Wakelee HA, Gadgeel SM, Varga A, et al. Rociletinib in EGFRmutated non-small-cell lung cancer. N Engl J Med (2015) 372:1700-9. doi:10.1056/NEJMoa1413654

70. Camidge DR, Sequist LV, Soria JC, Wakelee HA, Ou SH, Goldman JW, et al. Activity of rociletinib in EGFR mutant NSCLC patients with a history of CNS involvement. Presented at the 16th World Conference on Lung Cancer. J Thorac Oncol (2015) Volume 10(Suppl 2).

71. Gadgeel S, Chen W, Piotrowska Z, Goldman JW, Wakelee H, Camidge DR, et al. P3.02b-115 clinical activity of osimertinib in EGFR mutation positive non-small cell lung cancer (NSCLC) patients (Pts) previously treated with rociletinib. J Thorac Oncol (2017) 12(Suppl 1):S1263. doi:10.1016/j.jtho. 2016.11.1783

72. Zeng Q, Wang J, Cheng Z, Chen K, Johnstrom P, Varnas K, et al. Discovery and evaluation of clinical candidate AZD3759, a potent, oral active, central nervous system-penetrant, epidermal growth factor receptor tyrosine kinase inhibitor. J Med Chem (2015) 58(20):8200-15. doi:10.1021/acs.jmedchem. $5 \mathrm{~b} 01073$

73. Yang Z, Guo Q, Wang Y, Chen K, Zhang L, Cheng Z, et al. AZD3759, a BBB-penetrating EGFR inhibitor for the treatment of EGFR mutant NSCLC with CNS metastases. Sci Transl Med (2016) 8(368):368ra172. doi:10.1126/ scitranslmed.aag0976

74. Ahn MJ, Kim DW, Cho BC, Kim SW, Lee JS, Ahn JS, et al. Phase I study (BLOOM) of AZD3759, a BBB penetrable EGFR inhibitor, in patients with TKI-naïve, EGFRm NSCLC with CNS metastases. JClin Oncol (2017) 35(no.15_suppl):2006-2006. doi:10.1200/JCO.2017.35.15_suppl.2006

75. Tonra JR, Poyurovsky M, Liu KG, Patel J, Rao N, Tilton R, et al. KD019: blood brain barrier penetrant HER2/neu, Src, and EGFR inhibitor. Cancer Res (2015) 75(15 Suppl):2590. doi:10.1158/1538-7445.AM2015-2590

76. Berz D, Subramaniam DS, Tonra JR, Berger M, Camidge DR. Tesevatinib in NSCLC patients with EGFR activating mutations and brain metastases (BM) or leptomeningeal metastases (LM). J Thorac Oncol (2017) 12(1):S942-3. doi:10.1016/j.jtho.2016.11.1297

77. Zhang J, Yu J, Sun X, Meng X. Epidermal growth factor receptor tyrosine kinase inhibitors in the treatment of central nerve system metastases from non-small cell lung cancer. Cancer Lett (2014) 351(1):6-12. doi:10.1016/j. canlet.2014.04.019

78. Huang SM, Li J, Armstrong EA, Harari PM. Modulation of radiation response and tumor-induced angiogenesis after epidermal growth factor receptor inhibition by ZD1839 (Iressa). Cancer Res (2002) 62(15):4300-6.

79. Chinnaiyan P, Huang S, Vallabhaneni G, Armstrong E, Varambally S, Tomlins SA, et al. Mechanisms of enhanced radiation response following epidermal growth factor receptor signaling inhibition by erlotinib (Tarceva). Cancer Res (2005) 65(8):3328-35. doi:10.1158/0008-5472.CAN-04-3547

80. Bianco C, Tortora G, Bianco R, Caputo R, Veneziani BM, Caputo R, et al. Enhancement of antitumor activity of ionizing radiation by combined treatment with selective epidermal growth factor receptor-tyrosine kinase inhibitor ZD1839 (Iressa). Clin Cancer Res (2002) 8(10):3250-8.

81. Wang Y, Li Y, Xia L, Niu K, Chen X, Lu D, et al. Continued EGFR-TKI with concurrent radiotherapy to improved time to progression (TTP) in patients with locally progressive non-small cell lung cancer (NSCLC) after front-line EGFR-TKI treatment. Clin Transl Oncol (2018) 20(3):366-73. doi:10.1007/ s12094-017-1723-1

82. Zheng H, Liu QX, Hou B, Zhou D, Li JM, Lu X, et al. Clinical outcomes of WBRT plus EGFR-TKIs versus WBRT or TKIs alone for the treatment of cerebral metastatic NSCLC patients: a meta-analysis. Oncotarget (2017) 8(34):57356-64. doi:10.18632/oncotarget.19054

83. Jiang T, Min W, Li Y, Yue Z, Wu C, Zhou C. Radiotherapy plus EGFR TKIs in non-small cell lung cancer patients with brain metastases: an update meta-analysis. Cancer Med (2016) 5(6):1055-65. doi:10.1002/cam4.673

84. Soon YY, Leong CN, Koh WY, Tham IWK. EGFR tyrosine kinase inhibitors versus cranial radiation therapy for EGFR mutant non-small cell lung cancer with brain metastases: a systematic review and meta-analysis. Radiother Oncol (2015) 114(2):167-72. doi:10.1016/j.radonc.2014.12.011 
85. Gerber NK, Yamada Y, Rimner A, Shi W, Riely GJ, Beal K, et al. Erlotinib versus radiation therapy for brain metastases in patients with EGFR-mutant lung adenocarcinoma. Int J Radiat Oncol Biol Phys (2014) 89(2):322-9. doi:10.1016/j.ijrobp.2014.02.022

86. Magnuson WJ, Lester-Coll NH, Wu AJ, Yang TJ, Lockney NA, Gerber NK, et al. Management of brain metastaseses in tyrosine Kinase inhibitor-naïve epidermal growth factor receptor-mutant non-small-cell lung cancer: a retrospective multi-institutional analysis. J Clin Oncol (2017) 35(10):1070-7. doi:10.1200/JCO.2016.69.7144

87. Goldberg SB, Gettinger SN, Mahajan A, Chiang AC, Herbst RS, Chiang AC, et al. Pembrolizumab for patients with melanoma or non-small-cell lung cancer and untreated brain metastases: early analysis of a non-randomised, open-label, phase 2 trial. Lancet Oncol (2016) 17(87):976-83. doi:10.1016/ S1470-2045(16)30053-5

88. Chen N, Fang W, Zhan J, Hong S, Tang Y, Kang S, et al. Upregulation of PD-L1 by EGFR activation mediates the immune escape in EGFR-driven NSCLC: implication for optional immune targeted therapy for NSCLC patients with EGFR mutation. J Thorac Oncol (2015) 10(6):910-23. doi:10.1097/ JTO.0000000000000500

89. Akbay EA, Koyama S, Carretero J, Altabef A, Tchaicha JH, Christensen CL, et al. Activation of the PD-1 pathway contributes to immune escape in EGFRdriven lung tumors. Cancer Discov (2013) 3(12):1355-63. doi:10.1158/21598290.CD-13-0310

90. Takamori S, Toyokawa G, Okamoto I, Takada K, Kozuma Y, Matsubara T, et al. Discrepancy in programmed cell death-ligand 1 between primary and metastatic non-small cell lung cancer. Anticancer Res (2017) 37(8):4223-8. doi:10.21873/anticanres.11813

91. Mansfield AS, Aubry MC, Moser JC, Harrington SM, Dronca RS, Park SS, et al. Temporal and spatial discordance of programmed cell death-ligand 1 expression and lymphocyte tumor infiltration between paired primary lesions and brain metastases in lung cancer. Ann Oncol (2016) 27(10):1953-8. doi:10.1093/annonc/mdw289

92. Berghoff AS, Inan C, Ricken G, Widhalm G, Dieckmann K, Birner P, et al. Tumor-Infiltrating Lymphocytes (TILS) and PD-L1 expression in non-small cell lung cancer brain metastases (BM) and matched primary tumors (PT). Ann Oncol (2014) 25:465-6. doi:10.1093/annonc/mdu466.1
93. Lee CK, Man J, Lor S, Links M, Gebski V, Mok T, et al. Checkpoint inhibitors in metastatic EGFR-mutated non-small cell lung cancer- a meta-analysis. J Thorac Oncol (2017) 12(2):403-7. doi:10.1016/j.jtho.2016.10.007

94. Wang J, Chen J, Guo Y, Wang B, Chu H. Strategies targeting angiogenesis in advanced non-small cell lung cancer. Oncotarget (2017) 8(32):53854-72. doi:10.18632/oncotarget.17957

95. Rosell R, Dafni U, Felip E, Curioni-Fontecedro A, Gautschi O, Peters S, et al. Erlotinib and bevacizumab in patients with advanced non-small-cell lung cancer and activating EGFR mutations (BELIEF): an international, multicenter, single-arm, phase 2 trial. Lancet Respir Med (2017) 5(5):435-44. doi:10.1016/ S2213-2600(17)30129-7

96. Letarte N, Bressler LR, Villano JL. Bevacizumab and central nervous system (CNS) hemorrhage. Cancer Chemother Pharmacol (2013) 71(6):1561-5. doi:10.1007/s00280-013-2155-4

97. Lin JJ, Cardarella S, Lydon CA, Dahlberg SE, Jackman DM, Janne PA, et al. Five-year survival in EGF-mutant metastatic lung adenocarcinoma treated with EGFR-TKIs. J Thorac Oncol (2016) 111(4):556-65. doi:10.1016/j.jtho. 2015.12.103

98. Brown PD, Pugh S, Laack NN, Wefel JS, Khuntia D, Meyers C, et al. Memantine for the prevention of cognitive dysfunction in patients receiving whole-brain radiotherapy: a randomized, double-blind, placebo-controlled trial. Neuro Oncol (2013) 15(10):1429-37. doi:10.1093/neuonc/not114

Conflict of Interest Statement: WK and NS do not have personal, professional, or financial relationships that constitute conflict of interest. DS has received honoraria for her role as advisory board member or speaker for Bristol Myers-Squibb, Takeda Oncology, and Astra Zeneca.

Copyright (c) 2018 Kelly, Shah and Subramaniam. This is an open-access article distributed under the terms of the Creative Commons Attribution License (CC BY). The use, distribution or reproduction in other forums is permitted, provided the original author(s) and the copyright owner are credited and that the original publication in this journal is cited, in accordance with accepted academic practice. No use, distribution or reproduction is permitted which does not comply with these terms. 